\title{
Mitigating Hg pollution by harnessing anaerobic microbial metabolism
}

Alexandre J. Poulain ${ }^{1}$, DANiel S. GRÉGOIRE ${ }^{2}$, NOÉMIE LAVOIE ${ }^{1}$ AND BENJAMIN STENZLER ${ }^{1}$

${ }^{1}$ Biology Department, University of Ottawa, Ottawa, ON, Canada (*correspondance: apoulain@uottawa.ca)

${ }^{2}$ Department of Biology, University of Waterloo, Waterloo, ON, Canada

$\mathrm{Hg}$ is a global priority contaminant due to the biomagnification of the potent neurotoxin methylmercury in foodwebs. The continued concerns surrounding Hg's impact on human health were underscored by the recent ratification of the UNEP Minamata Convention (2017) requiring governments to regulate $\mathrm{Hg}$ emissions, mitigate environmental impacts, and ban the export of $\mathrm{Hg}$ waste to other countries. With this new regulatory context, industries such as mining, must develop solutions to deal with $\mathrm{Hg}$ pollution.

One challenge in managing mining pollution is the volume of water stored in tailings ponds that has a large environmental footprint. This contaminated water can be stored for decades, creating longstanding liability issues that negatively affect environmental health and the social license mining companies needs to operate. Current solutions for treating Hg-containing water typically have high costs and energy demands, use harsh chemicals, and produce large amounts of secondary waste.

In this context, we relied on anaerobic metabolisms to provide a low energy and low cost approach to monitor and remove $\mathrm{Hg}$ from effluents. Using phylogenetically diverse microbes, we show that anoxygenic phototrophic and fermentative microorganisms can reduce $\mathrm{Hg}^{\mathrm{II}}$ to $\mathrm{Hg}^{0}[1,2]$. We linked this redox transformation to pyruvate metabolism and to the nutrients (e.g., $\mathrm{C}$ and $\mathrm{S}$ ) available to microbes [2,3], which availability and redox state can be used to tune the magnitude of $\mathrm{Hg}$ reduction. Furthermore, by using a newly developed anaerobic biosensor, we show that this process is most likely intracellular [3]. Here, we discuss how microbes naturally found in the environment can be used to remove $\mathrm{Hg}$ from water and, using biosensors, monitor the effectivness of this approach.

[1] Grégoire, S.D., Poulain, A.J., (2016) Nature Geoscience, $9: 121-125$

[2] Grégoire, S.D., Lavoie, N., Poulain, A.J. (2018) Environmental Science \& Technology, 52 : 4145-4153

[3] Lavoie, N., Grégoire, S.D., Stenzler, B., and Poulain A.J. (2020) Geobiology, 18 (1):70-79 